\title{
Relato de caso: síndrome de Guillain-Barré - atraso do desenvolvimento da linguagem
}

\author{
Case report: Guillain-Barre syndrome - \\ language development delay
}

\section{Dionísia Aparecida Cusin Lamônica ${ }^{1}$, Tatiane Cristina Pereira², Kellen Ribeiro Silva ${ }^{3}$, Andréa Cintra Lopes ${ }^{4}$}

\begin{abstract}
Lamônica DAC, Pereira TC, Silva KR, Lopes AC. Relato de caso: síndrome de Guillain-Barré - atraso do desenvolvimento da linguagem. Rev Med (São Paulo). 2009 jul.-dez.;88(3/4):199202.

RESUMO: O objetivo deste estudo foi descrever o desenvolvimento da síndrome de GuillainBarré e manifestações fonoaudiológicas. É relatado breve histórico do quadro clínico e reavaliação fonoaudiológica 7 meses após o início dos sintomas, por meio de aplicação de testes formais, informais e avaliação audiológica. Na reavaliação, os resultados indicaram comunicação intencional, funções primárias, restrita participação em atividade dialógica, produções de palavras isoladas, compreensão de ordens ligadas ao contexto, retorno das habilidades alimentares. Foi constatada normalidade da audição periférica. Hospitalização, condutas familiares frente à doença e ausência de atividades escolares influenciaram no desempenho comunicativo. O aparecimento da Síndrome de Guillain-Barré influenciou de forma negativa no desenvolvimento da linguagem, assim como a resposta familiar à condição da criança.
\end{abstract}

DESCRITORES: Síndrome de Guillain-Barré; Linguagem infantil; Transtornos do desenvolvimento da linguagem.

INTRODUÇÃO

Síndrome de Guillain-Barré (SGB)
refere-se à polirradiculoneuropatia
inflamatória desmielinizante aguda de fibras periféricas sensoriais e motoras, podendo atingir nervos cranianos; caracterizada pela ocorrência de ataque auto-imune agudo, com debilidade simétrica progressiva, variável e ascendente, comprometendo membros, tronco, musculatura facial e orofaringe ${ }^{1-3}$.

\footnotetext{
1. Fonoaudióloga, Professora Associada do Departamento de Fonoaudiologia da Faculdade de Odontologia de Bauru da Universidade de São Paulo - FOB/USP

2. Mestranda do Curso de Fonoaudiologia da Faculdade de Odontologia de Bauru da Universidade de São Paulo - FOB/USP.

3. Neurologista infantil pela Universidade Estadual Paulista, FMB com especialização em neurofisiologia e ênfase em Eletroencefalograma Pós-Graduação em Medicina do Sono pela UNIFESP, Médica do Hospital Estadual de Bauru.

4. Fonoaudióloga, Professora Doutora do Departamento de Fonoaudiologia da Faculdade de Odontologia de Bauru da Universidade de São Paulo - FOB/USP

Endereço para Correspondência: Dionísia Aparecida Cusin Lamônica. Via Puccini 1-16, Residencial Tívoli 1. Bairro Tívoli 1; Bauru SP
} CEP: 170530-095. e-mail: dionelam@uol.com.br 
Ocorre entre 0,5 a 1,5 em 100.000 menores de dezoito anos ${ }^{3}$. Tem predomínio no sexo masculino e é rara em crianças pequenas ${ }^{4}$. Os sintomas típicos são: fraqueza muscular ou paralisia, diminuição da sensibilidade e dor tendinosa. Pode ocorrer visão confusa, dificuldade de movimentação dos músculos da face, alteração da respiração e da deglutição ${ }^{3-6}$. A fase inicial é acompanhada por piora dos sintomas ocorrendo uma fase de melhora seguida de estabilidade ${ }^{2,6}$. O diagnóstico de doenças graves em crianças tende a causar comportamentos de superproteção com interferência no desenvolvimento infantil ${ }^{5}$. Diante do exposto, o objetivo deste estudo foi descrever o caso clínico de uma criança que teve diagnóstico de polirradiculoneuropatia inflamatória e queixa de atraso no desenvolvimento da linguagem, avaliado aos 24 e 31 meses.

\section{MÉTODO}

Protocolo de aprovação do Comitê de Ética em Pesquisa número 66/2008.

Segundo filho de casal não consangüíneo, sem histórico de intercorrência de gestação e parto, desenvolvimento neuropsicomotor e linguagem dentro dos parâmetros de normalidade. Aos 24 meses, apresentou febre alta, diarréia e pneumonia e, em oito dias ficou paralisado e parou de se comunicar. O exame eletromiográficono indicou como conclusão: "Polineuropatia sensitivo-motora, desmielinizante aguda, compatível com Síndrome de Guillain-Barré. Ficou hospitalizado por 28 dias. O retorno das habilidades motoras ocorreu no período de seis meses, aproximadamente. Foi informado que a criança, durante esse período, realizava tratamento de fisioterapia. Os procedimentos de avaliação propostos foram: Observação do Comportamento Comunicativo (OCC), Escala de Desenvolvimento Comportamental Gesell e Amatruda - ECGA ${ }^{6}$; Early Language Milestone Scale - EELM(7), avaliação da audição e das funções orais.

\section{RESULTADOS}

$\mathrm{Na}$ avaliação fonoaudiológica inicial (aos 24 meses), realizada por meio da observação do comportamento comunicativo (OCC), verificou-se que não apresentava intenção comunicativa, prostrado, olhar ausente e dificuldade nas funções orais (sucção, mastigação e disfagia), e que não reagia para atividades lúdicas. A Escala de Desenvolvimento Comportamental Gesell e Amatruda - ECGA $^{6}$ e a Early Language Milestone Scale - EELM ${ }^{7}$, não foram aplicadas, em virtude da falta de responsividade do paciente.
A reavaliação ocorreu aos 31 meses. Ressalta-se que nessa época a mãe realizava todas as atividades diárias para o filho, mesmo após o retorno das funções motoras. Esse deixou de freqüentar a creche e outros ambientes sociais sem a presença da mãe.

Na OCC observou-se: comunicação intencional com funções primárias (instrumental e de protesto); restrita participação em atividade dialógica por meios verbais com produções de palavras isoladas; compreensão de ordens simples situacionais ligadas ao contexto imediato, acompanhadas ou não por gestos. Desistia das atividades propostas quando surgia algum obstáculo, solicitando sempre auxílio da mãe, que participou de todas as sessões de avaliação. Explorou brinquedos de maneira funcional e fez uso convencional de alguns objetos. Na ELM, obteve escores compatíveis com 18 meses na função auditiva expressiva; nas funções auditiva receptiva e visual, obteve escores compatíveis com 24 meses. Na ECGA observou-se: comportamento adaptativo, motor grosseiro e motor delicado compatível com 20 meses e pessoal-social e de linguagem compatível com 24 meses. Avaliação audiológica, realizada por meio da audiometria com reforço visual, avaliação do comportamento auditivo e imitanciometria, indicaram audição periférica dentro dos padrões de normalidade. Observou-se retorno das funções orais de sucção, mastigação e deglutição.

\section{DISCUSSÃO}

No início dos sintomas, a criança perdeu habilidades ${ }^{1-6}$, ficou hospitalizada necessitando de cuidados especiais da família. A literatura apresenta que a SGB evolui em três fases denominadas progressão, estabilização e regressão ${ }^{2,5}$, e que cerca de $90 \%$ recuperam-se por completo ${ }^{5}$, mas a recuperação das seqüelas pode não ser total, mantendo seqüelas motoras e sensoriais ${ }^{4,5}$. Nesse caso, após o período de recuperação previsto ${ }^{2,6}$, as habilidades motoras se encontravam inferiores à faixa etária, apesar da recuperação das funções como marcha, agarrar objetos, mastigação e deglutição. A linguagem expressiva encontrava-se mais prejudicada do que a receptiva. Apresentava prejuízo na área pessoal-social. Alterações no desenvolvimento ou desempenho da linguagem, receptiva e/ou expressiva, interferem em outros campos do desenvolvimento, principalmente na área pessoal-social, assim como esta área interfere no desenvolvimento e desempenho da linguagem. A perda das habilidades, hospitalização e superproteção podem proporcionar interferências no desenvolvimento infantil pela dificuldade de atuação 
Lamônica DAC, et al. Relato de caso: síndrome de Guillain-Barré.

com o meio. Nessas circunstâncias, a criança pode ir perdendo oportunidades de viabilizar seu repertório linguístico, pois o desenvolvimento da linguagem ocorre por ações integradas do próprio organismo às disposições psicomotoras, com interferência do ambiente, influenciando no processo maturacional e no desenvolvimento do processamento das informações ${ }^{8}$. Infere-se que a condição da doença, os efeitos psicológicos da família com o episódio da doença e a superproteção familiar também interferiram nesses achados ${ }^{5}$, pois a criança perdeu na interação ambiental e deixou de usar seu repertório de habilidades, com prejuízo nas áreas pessoal-social e linguística. Cabe ressaltar que, nesse caso, a família (principalmente a mãe) atendia e tinha uma atitude de realizar todas as atividades de vida diária para e pela criança. Infere-se que esse comportamento tenha influenciado no desenvolvimento da linguagem dessa criança, promovendo o atraso verificado. Um estudo 6 enfocou esse aspecto, apresentando a necessidade de tratamento multidisciplinar com atenção à família. A percepção dos pais de que a criança está particularmente vulnerável por problemas em sua saúde pode contribuir para ações superprotetoras, reduzindo as possibilidades de estimulação ambiental, de modo que essa criança passe a perder oportunidade de apreender informações qualitativas e quantitativas do ambiente. Dessa forma, é necessário atenção para os efeitos secundários desses comportamentos que poderão interferir no desenvolvimento global da criança. Os profissionais que atendem crianças que passaram por períodos de internação por motivo de doenças podem contribuir com orientações sobre a importância do retorno de rotinas diárias e da estimulação do ambiente prevenindo alterações do desenvolvimento infantil.

\section{CONCLUSÃO}

A Síndrome de Guillain-Barré contribuiu para o atraso das áreas motora, pessoal-social e de linguagem, provocada provavelmente pela dificuldade de exploração do ambiente pela criança e pela postura de superproteção familiar. Inferese que o atraso das habilidades comunicativas verificadas seja secundário à SGB. É importante que os profissionais fiquem atentos para orientar os familiares sobre estratégias de estimulação do desenvolvimento infantil na presença de qualquer doença que comprometa a saúde da criança.

Lamônica DAC, Pereira TC, Silva KR, Lopes AC. Case report: Guillain-Barre syndrome language development delay. Rev Med (São Paulo). 2009 jul.-dez.;88(3/4):199-202.

\begin{abstract}
The aim of the study was to describe the Guillain-Barré syndrome development and speech and language pathology manifestations. It describes the clinical picture of a speech and language pathology, and the revaluation 7 months after the symptoms beginning, through formal and informal tests application and auditory evaluation. In the revaluation, the results showed intentional communication, primary functions, restricted participation in dialogic activity, isolated words productions, orders understanding linked to the context, alimentary abilities return. Peripheral audition normality. Hospitalization, family conducts front to the disease and absence of school activities influenced in the communicative acting. The Guillain-Barré syndrome emergence, as well as the family answer to the child's condition, influenced in a negative way the language development.
\end{abstract}

KEY WORDS: Guillain-Barre syndrome; Child language; Language development disorders.

\title{
REFERÊNCIAS
}

1. Chan A, Gold R. Neuropsychological-psychiatric deficits in immune-mediated neuropathies. J Neurol. 2007:254(Suppl 2):II93-5.

2. Kalita J; Misra UK; Dias, M. Neurophisiological criteria in the diagnosis of different clinical types of GuillainBarré syndrome. J Neurol Neurosurg Psychiatry.
2008:79(1):289-93.

3. Lestayo-O'farril Z, Hernandez-Cáceres JL. Análisis del comportamiento del síndrome de Guillain-Barré. Rev Neurol. 2008;46(4):230-7.

4. Cerisola-Cardoso A, Capote-Moreira G, Scavone-Mauro 
C. Guillain-Barré syndrome in paediatrics. Differents forms of presentation and difficulties in reaching and early diagnosis Rev Neurol. 2007;44(12):725-32.

5. Agrawal S, Peake, D Whitehouse WP. Management of Children with Guillain-Barré Syndrome. Arch Dis Child Educ Pract. 2007.92(6)161-8.

6. Pao, M, Ballard ED, Donald L, Rosenstein MD. Growing up in the hospital. JAMA. 2007;297(24):2754-5.

7. Gesell A. Amatruda, CS. Diagnóstico do desenvolvimento; avaliação do desenvolvimento neuropsicológico no latente e na criança pequena - o normal e o patológico. Rio de Janeiro: Atheneu; 2000.

8. Coplan J. Early language milestone scale. Austin: ProEd; 1983.

9. Lamônica DAC, Ferraz PMDP. Leucomalácia periventricular e diplegia espástica: implicações nas habilidades psicolinguísticas. Pró-Fono Rev Atual Científica. 2007;19(4):357-63. 